\title{
METODOLOGIA DE DESDOBRAMENTO DA GESTÃO ESTRATÉGICA EM UNIDADE JUDICIÁRIA: UM MODELO DE SUCESSO?
}

Ricardo Gagliardi ${ }^{*}$

\section{RESUMO:}

O objetivo da pesquisa foi o de analisar os fatores que determinaram maior grau de eficácia da gestão, como tendência, na unidade judiciária da Comarca de Colméia, estado do Tocantins. O estudo se realizou por meio da observação, da pesquisa documental, e em revisão de literatura. Concluíram-se quatro fatores preponderantes para o bom resultado como tendência favorável ao longo dos anos. O que diferenciou a unidade pesquisada das demais foi à adoção de um sistema de gestão da governança judiciária, o maior envolvimento da liderança e da equipe de trabalho, e a persistência no modelo de gestão.

PALAVRAS-CHAVE: Governança; Planejamento; Razoável Duração do Processo; Liderança; Metodologia da Gestão.

\section{METHODOLOGY FOR DEPLOYING STRATEGIC MANAGEMENT IN A JUDICIAL UNIT: A SUCCESSFUL MODEL?}

\begin{abstract}
The objective of the research was to analyze the factors that determined a higher degree of management effectiveness, as a trend, in the judicial unit of Colmeia, state of Tocantins. The study was carried out through observation, documentary research, and in a literature review. Four major factors for the good result were concluded as a favorable trend over the years. What differentiated the researched unit from the others was the adoption of a judicial governance management system, the greater involvement of the leadership and the work team, and the persistence in the management model.
\end{abstract}

KEYWORDS: Governance; Planning; Reasonable Process Duration; Leadership; Management Methodology.

\section{CONSIDERAÇÕES INICIAIS}

A resposta estatal judiciária em geral no Brasil é sistematicamente morosa, por isso, inadequada, não suprindo os preceitos constitucionais. Segundo os dados do relatório Justiça em Números do Conselho Nacional de Justiça (BRASIL, 2020), em média, na justiça estadual, entre a distribuição e a sentença do juiz de $1^{\circ}$ grau, decorre tempo de 02 anos e 05 meses. No Tocantins, a média em 2019 foi de 01 ano e 08 meses.

\footnotetext{
* Juiz de Direito e Gestor Público. Doutorando em Teoria de Estado e Direito Constitucional pela Pontifícia Universidade Católica do Rio de Janeiro. Mestre em Prestação Jurisdicional e Direitos Humanos pela Universidade Federal do Tocantins. E-mail: reiricardo2007@gmail.com.
} 
Mesmo com a inserção por emenda constitucional de forma expressa dos princípios da eficiência e da razoável duração do processo, em 1998 e 2004, respectivamente, ainda assim, de forma geral, a resposta judicial apresenta-se além ou muito além dos prazos aritméticos fincados em lei.

A eficiência é um dos princípios balizadores do administrador público, da área judiciária, inserido expressamente na Constituição brasileira em 1998, por meio da Emenda 19 (BRASIL, 1988). Relaciona-se ao modelo da administração pública gerencial, voltada para o cidadão-cliente (BRESSER-PEREIRA, 2000, p. 16-17). Dentro da administração pública, eficiência é "oferecer à sociedade um serviço público de melhor qualidade, em que o critério de êxito seja sempre o do melhor atendimento ao cidadão-cliente a um custo menor" (BRESSER-PEREIRA, 2000, p. 18).

Este princípio abrange os conceitos da teoria administrativos de eficiência, eficácia e efetividade (CASTRO, 2006, p. 9). Ponto fulcral são os líderes aderirem aos seus argumentos para a melhoria contínua de desempenho da organização (GIESKE, BUUREN, BEKKERS, 2016).

Por sua vez, o princípio da razoável duração do processo foi inserido na Constituição da República Brasileira em 2004, por meio da Emenda 45 (BRASIL, 1988), como direito fundamental de eficácia plena e aplicabilidade imediata. Estabeleceu-se no inciso LXXVIII, do art. $5^{\circ}$, da Constituição, o direito consagrado a todos, no âmbito judicial e administrativo, da razoável duração do processo e dos meios que garantam a celeridade de sua tramitação.

Um dos fatores preponderantes para o não cumprimento dos prazos refere-se ao aspecto da gestão interna das unidades judiciárias (ARRUDA, 2006, p. 128; FARIA, 2013, p. 112-114).

Nesse sentido, em algumas unidades judiciárias pode-se observar uma diferenciação nos resultados. Como se fossem ilhas de excelência, em algumas delas observam-se fatores que a diferenciaram e garantiram o cumprimento de seus objetivos (DEOLINDO, 2010; OLINTO, SILVA, 2017 VALLE, 2017).

Dessa forma, o objetivo do artigo foi o de analisar os fatores que determinaram maior grau de eficácia da gestão desenvolvida na unidade judiciária de Colméia, no estado do Tocantins.

Para o desenvolvimento do artigo, utilizou-se a metodologia dedutiva, com base na pesquisa bibliográfica, documental e exploratória sobre o assunto, entre os anos de 2015 a 
2019. A unidade judiciária foi incluída no estudo tendo em vista seus resultados, a experiência do pesquisador na observação e acompanhamento como membro parte da gestão, e o conhecimento da gestão aplicada diferenciada com relação às demais unidades judiciárias de seu grupo.

Sua análise inicial parte de pesquisa documental que demonstra o resultado da unidade judiciária em estudo, componente do grupo de segunda entrância, do Estado do Tocantins, considerando as metas estabelecidas pelo nível estratégico da administração superior (CNJ e TJTO). O estudo relaciona os resultados anuais da unidade em estudo consigo mesma, com as unidades de mesmo grupo, e realiza uma comparação com as Comarcas que tradicionalmente possuem os melhores resultados, em uma análise mais próxima de distribuição de processos, estrutura e acervo.

Os resultados dos dados foram fornecidos pelo Tribunal de Justiça do Tocantins, por meio da Coordenadoria de Gestão Estratégica, por meio da Assessoria de Estatística (COGES), e Corregedoria-Geral de Justiça (CGJ), dos anos de 2015 a 2019. Sua análise partiu do conhecimento das condições, como estrutura predial, número de pessoas, equipamentos e materiais, e sistema de gestão da governança adotado.

$\mathrm{Na}$ sequência, foi realizada uma revisão sistemática de literatura, abrangendo os descritores, juntos ou intercalados: organização judiciária, unidade judiciária e metodologia de gestão, possibilitando uma análise mais aprofundada dos resultados da pesquisa, junto aos bancos de dados: Periódicos CAPES (Coordenação de Aperfeiçoamento de Pessoal de Nível Superior), Google Scholar, SciELO (Scientific Electronic Library Online), BDTD (Biblioteca Digital Brasileira de Teses e Dissertações), e estudo analítico de documentos produzidos pelos Tribunais do País, relacionados as suas gestões, por meio de seus sítios eletrônicos oficiais.

\section{MODELO DE GESTÃO DA UNIDADE JUDICIÁRIA EM ESTUDO}

A unidade judiciária em estudo trata-se da Comarca de Colméia, unidade de $2^{\mathrm{a}}$ entrância do Poder Judiciário do Tocantins, tem sede razoavelmente adequada, em bom estado de conservação, cumpre aos anseios quanto à quantidade e tamanho de salas, que são devidamente climatizadas, e possui equipamentos e outros materiais suficientes para a realização do trabalho. 
Durante o tempo de estudo, entre 2015 a 2019, pode-se observar que no período houve um magistrado titular, que assumiu as funções de diretor do foro, na área técnicaadministrativa, e de juiz de direito, na área técnica judicial. Há três escrivanias. Uma se circunscreve à área criminal (dois servidores efetivos, e um estagiário), que se desmembra em um CEPEMA - Central de Apoio das Penas e Medidas Alternativas (duas servidoras cedidas pelo Município e mais três servidoras contratadas por meio do GGEM - Grupo de Gestão das Equipes Multidisciplinares). As demais, nas áreas cíveis (quatro servidores efetivos, e dois estagiários). A unidade conta com um CEJUSC - Centro Judiciário de Solução de Conflitos e Cidadania (um servidor contratado), que atua nas audiências de conciliação. Há três oficiais de justiça efetivos e um contador efetivo. A Diretoria do Foro é dotada de um servidor comissionado, e o gabinete do juiz possui dois servidores comissionados, na assessoria, e um estagiário. No total, a equipe é composta de um magistrado, oito servidores efetivos da organização, três servidores efetivos de outras organizações, três servidores comissionados, e quatro são contratados quando necessários, conforme a demanda do serviço, considerando a temporariedade e a excepcionalidade. Uma equipe de três pessoas executam funções terceirizadas de limpeza, atendimento e segurança.

O sistema eletrônico adotado pelo Tribunal de Justiça (TJ) é o e-Proc, funcionando na localidade desde maio de 2012, sendo considerada Comarca 100\% digital a partir de agosto de 2014. O SEEU é o sistema adotado com relação às execuções penais, a partir de 2019.

Na unidade, desde o início de 2014, adota-se um sistema de gestão por objetivos, utilizando-se do instrumento do Balanced Scorecard (BSC), adotado pelo Conselho Nacional de Justiça (BRASIL, CNJ, 2009) e todos os Tribunais do País, adaptados à realidade da administração pública judiciária, baseado em planejamento prévio (coleta de dados, diagnóstico e formulação da estratégia), implementação e execução por meio do desenvolvimento de indicadores, metas, e ações, e acompanhamento e controle por meio da análise de indicadores técnicos, acompanhamento de metas e promoção de reajustes (CAMPELO, 2007, p. 131-132).

Antes disso, sem uma administração voltada aos resultados, não havia foco, mensuração, avaliação e nem controle dos resultados, embora o Conselho Nacional de Justiça $(\mathrm{CNJ})$ e o TJ tenham realizado movimentos voltados à gestão estratégica, a partir do final de 2007. 
Os desenhos iniciais para a melhor governança partiram do conhecimento da estratégia superior (CNJ e TJTO), seu alinhamento, por meio de desdobramento da estratégia aos níveis tático e operacional.

Para tanto, alicerçado no diagnóstico prévio, desenvolveu-se a filosofia gerencial da unidade judiciária. A partir das perspectivas e macrodesafios estratégicos, estabeleceram-se objetivos táticos, indicadores, metas e ações. O acompanhamento desenvolvido teve suporte na técnica do PDCA (NOGUEIRA, 2011, p. 55 e 64).

A unidade subdividiu-se em seis setores operacionais (escrivania $1^{\circ}$ Cível, escrivania $2^{\circ}$ Cível, escrivania Criminal, Central de Mandados, Gabinete do Juiz e Diretoria de Foro). Em cada setor foi nominado um líder. Uma Portaria do diretor do foro regulamentou o processo metodológico e suas atribuições.

No processo, realizaram-se planejamento tático, por meio de reunião conjunta de todas as equipes, sendo definidas, depois do diagnóstico, além da filosofia da unidade, suas metas, e principais ações. Foram definidas também as metas operacionais de cada setor. Cada equipe realizava em seguida, dias após, seu planejamento operacional, organizando as ações mais prudentes para cumprir suas metas.

A filosofia gerencial estipulada na Comarca foi formada pela missão, visão de futuro, valores, e objetivos táticos. Por ser de médio prazo, a cada um ou dois anos pode ser alterada. Uma das mudanças ocorreu entre os anos de 2019 e 2020, com o fim de deixá-las mais simples e transparentes, e mais alinhadas à organização, nível estratégico, tanto nacional (CNJ) como regional (TJTO).

A missão foi entalhada nos seguintes termos: "Prestar serviços jurisdicionais de modo efetivo". Chama a atenção que o serviço prestado deve ser efetivo.

A missão em nível nacional traduz-se em "realizar Justiça". O conceito de efetividade gerencial segue a análise mais abrangente do que cumprir sua função de modo mais econômico (eficiência) e produzindo bons resultados finais, relacionando as metas alcançadas e as metas pretendidas (eficácia), sob pena de tornar o Judiciário em atividade mecânica, sem valor e significado real.

A efetividade adéqua-se aos resultados produzidos e às melhorias como benefícios para a população (CASTRO, 2006, p. 5). Entende-se efetividade para fins do que se almeja gerencialmente é analisar se há ou não "a capacidade organizacional para ser eficaz ao longo 
do tempo", no sentido de sua continuidade, a partir da conceituação da Comissão Econômica para América Latina e Caribe (CEPAL) (1998, p. 18).

Nestes termos, a missão da comarca significa que a organização deve processar e julgar fatos e circunstâncias, envolvendo pessoas, em última instância, prestigiando-se antes outros meios pacíficos de solução de litígios, cumprindo-se os objetivos definidos por meio de metas de modo contínuo, sob o especial parâmetro de "sinalizadores" externos (BRASIL, STJ, 2018).

A visão de futuro foi assim configurada: "Ser reconhecida como uma Comarca que presta serviços de Justiça com qualidade e celeridade, colaborando para que a região se desenvolva nos aspectos educacional, social e econômico".

A descrição da visão de futuro estabelece forte conexão com os princípios da razoável duração do processo, que compreende agilidade e segurança jurídica, e está estritamente atada ao desenvolvimento socioeconômico, incluindo o aspecto educacional. A visão de futuro da Comarca alinha-se com a visão nacional e regional do Judiciário, possuindo os mesmos elementos.

Delinearam-se os valores: "Compromisso para com a Lei; Satisfação dos usuários do serviço; Valorização das Pessoas (público interno); Ética profissional plena; Integridade; Transparência; Agilidade; Inovação constante; Sustentabilidade; Segurança Jurídica; Acessibilidade; Eficiência.

Segundo a descrição desses valores, a legalidade em seus atos deve estar embutida nos valores profissionais e pessoais de seus colaboradores. Por isso, a decisão judicial deve preservar atributos como a imparcialidade e a equidade, sendo a ação dos colaboradores adstrita à impessoalidade. Argumentos legais devem estar em superioridade aos argumentos de ordem pessoal.

No planejamento se desenhou que o foco do serviço prestado é a sociedade e o cidadão, usuário direto ou indireto do serviço, bem como os operadores do direito.

Os colaboradores e as equipes de trabalho devem ser constantemente valorizados pela importância do trabalho que realizam. A falta de comprometimento dos líderes e colaboradores pode ser um dos principais problemas das organizações (OLIVEIRA, 2009, p. 311). O melhor desenvolvimento da gestão se faz com a colaboração dos servidores (NOGUEIRA, 2011, p. 69; RIBEIRO, 2002, p. 47). 
A inovação nos processos e nas ações tornou-se um valor de denotada importância, já que faz romper os limites impostos pela rotina, e propicia e melhoria constante. Foram algumas inovações realizadas nos procedimentos padrões e modos de trabalho, em nível local, nos dois anos, e/ou ainda em funcionamento: Criação e desenvolvimento de sistema de gestão, baseado no Balanced Scorecard (BSC) adaptado pelo CNJ, por meio de planejamento tático anual; Segmentação do planejamento tático ao nível operacional, a partir do ano de 2019; Mensuração da pontualidade para o início das audiências, com foco no usuário; Criação de método de produção de provas nas ações previdenciárias, com a realização de termo de constatação, a fim de identificar a atividade rural desenvolvida, e busca de dados pessoais do interessado e/ou cônjuge ou convivente, por meio do sistema e-Proc para cruzamento de informações; Implantação do CEPEMA (Central de Execuções de Penas e Medidas Alternativas), com o fim de acompanhar, orientar, monitorar, fiscalizar, e assessorar, de forma diferenciada, a cada caso/indivíduo, em cumprimento de penas e medidas criminais, e medidas socioeducativas impostas a adolescentes; Método de seleção de assessores e estagiários; Realização de plano de ação a fim de gerar um fluxo processual para não haver processos conclusos há mais de 30 dias; Utilização de minutas padronizadas e movimentação de processos em bloco, relacionadas às demandas repetitivas.

A sustentabilidade é termo genérico para designar a capacidade de sustentação ou conservação de um processo ou sistema. Em um plano de sistema global, envolvendo três dimensões, a econômica, a social e a ambiental, passou a ser considerada pelos países componentes da ONU como um plano de ação global, voltado às pessoas, ao planeta e à prosperidade. Busca fortalecer a paz universal e a liberdade, erradicar a pobreza em todas as suas formas. A sustentabilidade se traduz em 17 Objetivos de Desenvolvimento Sustentável e 169 metas em uma agenda universal, em um prazo de 15 anos, nas seguintes áreas: Pessoas, Planeta, Prosperidade, Paz e Parceria (ONU, 2015). Esse valor ingressou entre os atributos de valor da gestão estratégica do Poder Judiciário e da unidade em estudo.

Os objetivos táticos e operacionais da unidade estão centrados nas perspectivas e macrodesafios da gestão estratégica do Poder Judiciário Nacional e Regional.

As perspectivas foram definidas em três eixos: sociedade (impacto social), processos internos (atividades-fim), e pessoas e recursos (atividades-meio).

São dois os principais objetivos voltados ao produto/processo da prestação jurisdicional, de modo a garantir a agilidade e a produtividade: 1) focado no tempo de 
julgamento dos processos, ou seja, quanto menor o tempo em média de julgamento dos processos melhor para o cumprimento do objetivo; 2) direcionado ao cumprimento da demanda.

A gestão da unidade judiciária em estudo acompanhou em 2019 as seguintes perspectivas/objetivos do planejamento estratégico (2015-2020) do TJTO, e desenvolveu os seguintes indicadores/metas:

1. Sociedade, objetivo: garantia dos direitos e cidadania, com as seguintes metas: 20 (sinalizador com o fim de reduzir o índice de homicídio; 29 (influenciar melhorias no sistema carcerário); 30 (possibilitar a instalação de sistemas de ensino à distância junto aos condenados a penas criminais; 32 (influenciar o desenvolvimento de cursos interdisciplinares nas Escolas de ensino médio, voltados a fomentar a reflexão sobre atos de preservação de conflitos sociais, valores ligados à cidadania); 33 (desenvolvimento de oficinas de parentalidade); influenciar autoridades a adotarem e adquirirem os meios para a escuta especializada e depoimento especial de crianças e adolescentes); e ainda as metas: 27 (medir o índice de satisfação do usuário); e 28 (medir o índice de satisfação e a percepção dos operadores de direito e outros parceiros).

2. Processos Internos, objetivo: combate à corrupção e à improbidade administrativa, com a seguinte meta: 4 do $\mathrm{CNJ}$ (julgar processos relacionados às ações de improbidade administrativa e às ações penais que apurem crimes contra a administração pública).

3. Processos Internos, objetivo: celeridade e produtividade na prestação jurisdicional, com as seguintes metas: 1 do CNJ (julgar quantidade maior de ações de conhecimento do que os distribuídos no ano); 2 do CNJ (julgar processos antigos - distribuídos até 31.12.2015); 1 (atendimento à demanda ou vazão processual); 2 (taxa de congestionamento); 3 (redução do acervo); 13 (cumprir os processos em até 30 dias); 14 (julgar processos antigos - distribuídos até 31.12.2017); 15 (julgar processos conclusos em até 30 dias); 16 (dar o andamento do processo concluso em até 30 dias); 17 (cumprir os mandados judiciais em até 10 dias).

4. Processos Internos, objetivo: aprimoramento da gestão da justiça criminal, com as seguintes metas: 7.1 (grau de julgamento de processos novos, criminais, de conhecimento, mais complexos); 7.2 (reduzir o tempo de julgamento dos processos criminais, de conhecimento, mais complexos); 8.1 (grau de julgamento de processos novos, criminais, de conhecimento, menos complexos); 8.2 (reduzir o tempo de julgamento dos processos criminais, de conhecimento, menos complexos); 9.1 (grau de julgamento de processos novos, 
criminais, de conhecimento, da $1^{\mathrm{a}}$ fase do procedimento do Júri); 9.2 (reduzir o tempo de julgamento dos processos criminais, de conhecimento, da $1^{\text {a }}$ fase do procedimento do Júri); 10.1 (grau de julgamento de processos novos, criminais, de conhecimento, da $2^{\mathrm{a}}$ fase do procedimento do Júri); 10.2 (reduzir o tempo de julgamento dos processos criminais, de conhecimento, da $2^{\mathrm{a}}$ fase do procedimento do Júri); 11.1 (grau de julgamento de TCO e outros incidentes criminais novos); 11.2 (reduzir o tempo de julgamento de TCO e outros incidentes criminais); 18 (realizar controle mensal de dados penais); 19.1 (grau de eficácia com base no índice de julgados de prescrição em ação penal); 19.2 (grau de eficácia com base no índice de julgados de prescrição em execução penal).

5. Processos Internos, com os objetivos: adoção de soluções alternativas de conflito, gestão de demandas repetitivas e dos grandes litigantes, impulso às execuções fiscais, cíveis e trabalhistas, foram resumidos no objetivo: aprimoramento da gestão da justiça cível, com as seguintes metas: 6 do CNJ (julgar ações coletivas); 4.1 (grau de julgamento de processos novos, cíveis, de conhecimento, mais complexos); 4.2 (reduzir o tempo de julgamento dos processos cíveis, de conhecimento, mais complexos); 5.1 (grau de julgamento de processos novos, cíveis, de conhecimento, menos complexos); 5.2 (reduzir o tempo de julgamento dos processos cíveis, de conhecimento, menos complexos); 6.1 (grau de julgamento de processos novos, cíveis, de execução, menos complexos); 6.2 (reduzir o tempo de julgamento dos processos cíveis, de execução, menos complexos).

6. Pessoas e recursos, objetivo: melhoria da gestão de pessoas, com as seguintes metas: 25 (manter satisfatória a satisfação dos colaboradores); e 26 (realizar SIPAT).

Pessoas e recursos, objetivo: melhoria da gestão de custos, com as seguintes metas: 21 (reduzir consumo de telefone); 22 (reduzir consumo de energia); 23 (reduzir consumo de papel); 24 (reduzir consumo de água).

7. Pessoas e recursos, objetivo: instituição da governança judiciária, resumido nos seguintes objetivos: aperfeiçoamento da gestão administrativa e da governança judiciária, com as seguintes metas: 12 (proferir decisões administrativas em tempo razoável); 31 (manter a rotina dos trabalhos do CEPEMA).

Verificando-se os gargalos de anos anteriores, em cada planejamento se desenhavam novas ações. Definiram-se os seguintes planos de ação: 06 planos de ação específicos para o planejamento tático e operacional; gerenciamento e manutenção dos processos em cumprimento dos prazos no tempo razoável e em até 30 dias; evitar audiências frustradas; 
organização de minutas de decisões em audiências; agendamentos de audiências por dia; planos de ação setoriais.

Foi elaborado o calendário anual com as datas previamente agendadas das reuniões de análise operacional, por setor (RAO), as reuniões de análise tática (RAT), e as demais ações de manutenção predial. O desenho programado para o acompanhamento setorial era mensal, depois do recebimento dos resultados dos indicadores do mês anterior. O diretor do foro presidia reuniões de análise tática a cada quatro meses, com o fim de analisar junto aos líderes os resultados, com o fim de manter ou alterar as ações desenvolvidas.

No entanto, por falta de repasse de dados pela administração superior e dificuldade de obter os dados, e ainda pela desmotivação dos líderes, ainda arraigados as suas rotinas, algumas reuniões não foram realizadas em 2019. Apenas uma reunião de reajuste foi efetivamente concluída.

\section{DOS RESULTADOS, DA DISCUSSÃO E ANÁLISE}

\subsection{Resultados de pesquisa}

Cada vez mais, a alta administração, em uma organização alicerçada em conhecimento, tem a principal função de fixar direções à organização, na formulação de objetivos, prioridades e estratégias (DRUCKER, 1980, p. 202-206).

E esse ainda é um dos cernes da questão. Os níveis tático e operacional das unidades da administração pública em geral carecem de um direcionamento padronizado da administração superior.

O planejamento estratégico exige etapas, de modo que as estratégias sejam divididas em subestratégias, denominados como planos estratégicos (longo prazo), táticos (médio prazo) e operacionais (curto prazo) (CHIAVENATO, 2014, p. 415-416).

O modelo desenvolvido observou o nível estratégico, alinhando-se, e desenvolveu sua estratégia (nível tático) e ainda oportunizou o desenvolvimento de planos setoriais (nível operacional), criando uma inovação dificilmente encontrada em outras unidades da Justiça.

Conforme relatório de planejamento tático da unidade, referente a 2019, passando da breve discussão do modelo metodológico ao resultado, de todas as metas, no total de 50, 25 foram cumpridas, 17 não foram atingidas e 08 não foram medidas, devido à indisponibilidade 
técnica do Tribunal. Ou seja, das metas apuradas, restou o índice aproximado de 60\% favorável. Esse é um fator aparentemente negativo. Talvez, a liderança da unidade deva pensar em inclusão de metas menos audaciosas ou em menor quantidade, já que merecem ser renovados os valores para fins de melhores resultados também no critério da governança judiciária. Além disso, a criação de indicadores e metas deve na medida do necessário estar alinhada à possibilidade de medição. Portanto, um número tão extenso de metas pode acabar prejudicando o foco no que mais interessa.

Por outro lado, a política de incentivo e criação de metas desafiadoras, por sua vez, gerou resultados positivos como tendência dos indicadores, considerados os últimos cinco anos.

Primeiramente porque passou a cumprir desde há dois anos, a partir de 2018, todas as metas nacionais e regionais, previstas nos planejamentos estratégicos do CNJ e do Tribunal, como Meta $01 \mathrm{CNJ}$ : resultado 106\%; Meta $02 \mathrm{CNJ}$ : resultado 120\%; Meta $04 \mathrm{CNJ}$ - combate à corrupção: resultado 100\%; Meta $06 \mathrm{CNJ}$ - ações coletivas: resultado 166\%; Meta $08 \mathrm{CNJ}$ violência doméstica contra a mulher: resultado 154\%; Meta 9 TJTO - Reduzir para 53\% a taxa de congestionamento processual em 2019: resultado 100\%; e Meta 10- atingir o índice de 1.400 processos julgados por magistrado/ano até 2020, de forma gradativa: os resultados foram alcançados em todos os anos: em 2016, com 1341 julgados (134\%), em 2017, com 1747 julgados (158\%), em 2018 com 1884 julgados (157\%), e em 2019 com 2362 julgados $(181 \%)$.

Em segundo lugar porque segue uma tendência de melhoria de todos os seus indicadores de controle, nos últimos cinco anos, como quantidade de acervo (3.771 processos, ao final de 2019 - redução de 3\%), índice de julgamento (2.362 processos - aumento de $121 \%$ ), índice de baixa processual (2.753 processos, aumento de 61\%), índice de audiências realizadas (1531 audiências - aumento de 70\%), tempo de julgamento de processos e taxa de congestionamento. Tem baixo índice de prescrição das ações e execuções penais.

O terceiro ponto a se considerar é que mesmo com a distribuição de processos novos ter aumentado em 109\% nos últimos 05 anos, ainda assim, o acervo reduziu em 3\%, houve aumento nos julgamentos em 121\%, aumento nas baixas processuais em $61 \%$, aumento na realização de audiências em $70 \%$, melhoria no tempo de julgamento médio de processo em $62 \%$, redução da taxa de congestionamento em queda de 11,8 pontos percentuais. Não houve processos conclusos há mais de 100 dias. 
Há que se considerar que todos os objetivos mensuráveis pela administração superior estão sendo cumpridos pela unidade judiciária há dois anos, mesmo com o aumento estrondoso da demanda nos últimos anos.

Em outra análise, comparam-se dados da unidade com o grupo de $2^{\mathrm{a}}$ Entrância.

Tabela 01 - Comparação da Comarca com as demais unidades de 2a Entrância (grupo).

\begin{tabular}{ccc}
\hline INDICADOR & UNIDADE & GRUPO \\
\hline ACERVO & $-3 \%$ & $+27 \%$ \\
DISTRIBUIÇÃO & $+109 \%$ & $+70 \%$ \\
JULGAMENTO & $+121 \%$ & $+83 \%$ \\
CLS + 100 dias & 0 (a partir 2018$)$ & Várias unidades \\
Tempo Julgamento & 463 dias & 655 dias \\
Baixa & $+61 \%$ & $+42 \%$ \\
Taxa Congestionamento & 57,8 & 64,8 \\
\hline
\end{tabular}

Fonte: COGES - Tribunal de Justiça do Tocantins, entre os anos de 2015 a 2019.

Pode-se verificar que enquanto o acervo da unidade em estudo reduziu em 3\%, o do grupo, aumento $27 \%$, mesmo a distribuição na unidade em estudo ter sido 38,54 pontos percentuais maiores do que a média do grupo. Não há processos conclusos há mais de 100 dias desde o ano de 2018, realidade diversa em boa parte das demais Comarcas. O tempo de julgamento do processo, em média, por dia, passou a ser menor que a do grupo a partir de 2018, e em 2019 encerrou em 29\% menor, em 463 dias. Houve aumento de julgamentos na Comarca maior do que a média do grupo em 46,14\%. A diferença de número de julgamento é de mais de $69 \%$. A Comarca baixou $66 \%$ mais processos do que a média do grupo, e realizou $113 \%$ mais audiências do que a média do grupo. A taxa de congestionamento tem diferença de 07 pontos percentuais com relação ao grupo.

Ou seja, embora trabalhe com a carga maior tanto em acervo como em histórico de distribuição, tem melhores resultados de eficiência e de eficácia contínua. Isso demonstra, ao contrário da média das demais unidades, uma evolução como tendência favorável concreta nos últimos anos.

Mesmo se comparando com Comarcas mais bem avaliadas do grupo de $2^{\mathrm{a}}$ Entrância, Alvorada e Miranorte, ainda assim, tem índices equivalentes ou superiores, como entre julgamento/distribuição de 0,72 (média de 5 anos) e 0,66 (2019), enquanto Alvorada 0,88 (média de 5 anos) e 0,66 (2019), e Miranorte 0,66 (média) e 0,62 (2019); entre acervo/distribuição de 1,63 (média de 5 anos) e 1,06 (2019), enquanto Alvorada 1,23 (média) e 1,27 (2019), e Miranorte 2,04 (média de 5 anos) e 1,83 (2019), e indicadores de melhorias 
contínuas em cinco anos, ou seja, melhor evolução, diferentemente das Comarcas citadas que apresentam maior oscilação e tendência de piora.

O tempo de julgamento em média do processo em 2019 na unidade chegou há 463 dias, com tendência de queda em 62\%. Alvorada teve o tempo de 526 dias em 2019, com tendência de alta de 28\%. Miranorte teve o tempo de julgamento em 777 dias em 2019, com tendência de alta de $6 \%$. A taxa de congestionamento da unidade em estudo teve tendência de queda em cinco anos de $11,8 \%$, enquanto que Alvorada e Miranorte tiveram tendências de queda menos acentuadas, de $3,5 \%$ e $1,4 \%$, respectivamente.

Em matéria de gestão de custo, eles se mostraram razoáveis. Foram despesas anuais: $\mathrm{R}$ \$ 2.149,01 de telefone, $\mathrm{R}$ \$ 28.971,91 de energia; 83 resmas de papel; e R\$: 3.240,08 e água/esgoto), embora seja possível melhores programações para seu uso sustentável.

É de asseverar que há algo diverso na unidade. Ela não se diferencia na quantidade superior de servidores, qualidade superior do prédio ou equipamentos e demais materiais, e nem na capacitação para o trabalho-fim dos colaboradores.

Como exemplo, cita-se a Comarca de Miranorte, referência entre as unidades de seu grupo. Enquanto esta unidade, entre 14/10/2018 a 14/10/2019, apresenta o índice de produtividade de servidor (IPS) em 140 atos anuais e 12 mensais, contando com 20 servidores e mais 03 assessores, a unidade em estudo, entre 10/03/2019 a 10/03/2020, produziu mais, com IPS de 174 ao ano e 15 ao mês, porém, com 14 servidores e 02 assessores (documento em anexo).

\subsection{Análise e discussão}

Quatro fatores foram identificados na pesquisa para os bons resultados: a liderança do juiz-gestor; a participação de toda a equipe de trabalho na construção do planejamento; a observação de uma metodologia de trabalho normatizada pela unidade, em nível tático e operacional, e dentro do alinhamento estratégico da administração superior; e a persistência da gestão e da metodologia durante anos.

Como primeiro fator que contribuiu ao alcance dos resultados, deve ser observado o critério da liderança do juiz-gestor e dos líderes setoriais.

Na unidade, demonstrou-se haver liderança em nível tático, e em níveis setoriais, que se envolveram com os problemas, suas soluções e com os resultados. Essa qualidade foi 
observada a partir da observação deste pesquisador quando da participação das reuniões, da construção do planejamento e dos relatórios de gestão realizados ao longo dos anos.

Para vários autores (ATAÍDE JÚNIOR, 2006, p.67; DEOLINDO, 2011, p. 69-70; FUIN, 2013, p. 108; NALINI, 2011, p. 31; RIBEIRO, 2019), a liderança do juiz de direito titular da unidade judiciária é fundamental para o alcance dos resultados almejados. Segundo a Resolução n ${ }^{\circ} 198$ do CNJ, art. $7^{\circ}$, cabe tal liderança aos juízes na execução do plano estratégico, sendo a responsabilidade de todos os servidores, especialmente daqueles em cargo ou função de chefia.

Sendo o Poder Judiciário uma instituição regulada pela Constituição, e o juiz o líder dos processos organizacionais decisórios, como se denota em outros estudos (GIESKE, BUUREN, BEKKERS, 2016; MOURA et al, 2019), a mudança institucional somente ocorre de forma verdadeira se seus atores principais, líderes e gestores, aderirem aos seus argumentos de busca contínua de melhores resultados.

Observou-se, por outro lado, a dificuldade da liderança nos setores operacionais, diante da ausência de reuniões mensais nos referidos setores. Isso demonstrou certa dificuldade nesse âmbito, sendo evidenciado um problema que pode estar ligado à ordem de comprometimento e/ou de capacitação com a função, sendo esta a principal hipótese, tendo em vista ao padrão hierarquizado tradicional e formal da administração pública brasileira.

$\mathrm{Na}$ perspectiva de governança interna, verifica-se ser muito importante a capacitação contínua dos líderes na gestão de seus setores. A parceria com a Escola Superior da Magistratura e Universidades seria uma ótima oportunidade.

O segundo fator observado se trata da participação e envolvimento da equipe de trabalho.

O fato de todos da equipe participarem do processo de construção da obra do planejamento, contribuindo para a coleta de dados, diagnóstico e da formulação das estratégias, apresentou-se com fator motivador e influenciador de boas práticas e desenvolvimento de novas ideias e ações, como se verificou nos resultados e na apresentação das práticas inovadoras.

A participação de todos, envolvendo e responsabilizando cada setor e cada líder nominado, tem o condão de gerar efeitos positivos ao longo prazo para a organização (NOGUEIRA, 2011; RIBEIRO, 2002). 
Como eventual dificuldade a ser enfrentada quanto ao pessoal, foi observado na unidade o aumento da demanda processual ao longo dos anos, o que poderia impactar futuramente na insuficiência de pessoal frente à tendência de alto índice de novas demandas. Se tal fato preponderar e a tecnologia não responder suficientemente esse fator deve ser repensado. Por enquanto não se verificou necessário, diante dos dados apresentados. A melhor e a contínua capacitação dos líderes nos ambientes de gestão, como já se tratou, é medida que se impõe para se melhorar a governança judiciária dos setores, de modo a se incentivar inovações, ações, reajustes e acompanhamentos contínuos.

O terceiro fator para os bons resultados obtidos pela unidade judicial se relaciona ao desenvolvimento e uso de uma metodologia de gestão, na forma de planejamentos tático e operacionais, de forma alinhada ao planejamento estratégico da organização.

A metodologia se desenvolveu em três fases: formulação e tradução da estratégia da unidade e dos setores, implementação e execução da estratégia, e o acompanhamento contínuo. Essa técnica está alicerçada pela teoria (CAMPELO, 2007, p. 131-132).

O acompanhamento e reajuste de ações de forma continuada, com base nos resultados dos indicadores, foi o elemento primordial para o melhor direcionamento da gestão na unidade.

O resultado desse estudo confirma a conclusão de outras pesquisas empíricas no sentido de que unidades judiciárias e administrativas têm demonstrado melhores resultados quando desenvolvem o seu planejamento gerencial, operacionado a partir do desdobramento da estratégia da administração superior ou pelo menos desenvolvem planos de ação, controlando os indicadores e as metas da administração superior (DEOLINDO, 2010; VALLE, 2017, p. 8-9), e ainda mais quando tais resultados perduram por anos e apresentam tendências de melhoria contínua, o que faz demonstrar a estabilidade das gestões (DINIZ, 2019; OLINTO, SILVA, 2017).

Segundo Valle (2017, p. 99-10), o planejamento gerencial pelas unidades judiciárias tem garantido o cumprimento das metas estipuladas pelo $\mathrm{CNJ}$, aumento da produtividade e da qualidade dos serviços, e melhoria da governança judiciária, o que se demonstrou com os dados obtidos. Destaque-se que o modelo aplicado na unidade em estudo vai mais além, pois apresenta um sistema de maior desdobramento estratégico, vindo a atingir o nível operacional.

Referidos estudos, no entanto, trazem a lume a reflexão de que sem a normatização de métodos gerenciais pela administração superior e sem a padronização dessa metodologia 
em manual e na capacitação adequada e contínua que possam traduzir a habilidade de saber fazer e a atitude de querer fazer (VALLE, 2017, p. 12-15), tais iniciativas isoladas de cada unidade, por si só, não são suficientes para angariar a mudança para a produção de melhores resultados como tendência ao longo dos anos (MOURA et al, 2019), ainda mais porque as pessoas e os lideres mudam, renovam-se, no entanto, nem sempre para melhor, do ponto de vista estritamente público.

Como destaca Santos (2017, p. 103), por exemplo, o Poder Judiciário, no Estado do Tocantins não dispõe de um plano que vise o alinhamento das unidades ao planejamento estratégico, exceto quanto à área de tecnologia da informação, e à mera comunicação da estratégia e a produção de indicadores.

Nesse ponto, destaca-se com o exposto a importância do desenvolvimento de método da gestão setorizada, descentralizada, de forma padronizada e contínua, como instrumentos eficazes em cada Tribunal. E esse é o cerne do conceito da governança pública.

Governança pode ser definida como

[...] a capacidade e as condições internas ao governo, para exercício de suas competências e alcance de seus objetivos. Diz respeito aos recursos técnicos, tecnológicos, de infraestrutura, de pessoal, dentre outros de que dispõe as estruturas governamentais para formular, planejar e implantar as políticas públicas, assim como acompanhar, avaliar e fiscalizar a sua execução e resultados objetivos (BRASIL, MPOG, 2014, p. 28).

A boa governança pública deve perseguir as seguintes qualidades: capacidade de gestão da instituição; capacidade para gerar valor para a sociedade; capacidade do sistema de liderança dos órgãos e setores, em atuar de forma coesa, capacitando e motivando seus colaboradores, e orientada para o alcance dos objetivos institucionais (BRASIL, MPOG, 2014, p. 21-22).

A governança institucional possui as seguintes dimensões: a formação e a gestão de líderes; a estruturação do processo decisório, voltada para a geração de valor social; a prática institucional de monitoramento e avaliação sistemáticos de seu desempenho, com base em indicadores, com vistas ao contínuo reposicionamento (BRASIL, MPOG, 2014, p. 22).

Seja qual for a metodologia utilizada, verifica-se essencial o direcionamento institucional padronizado, o envolvimento e capacitação da liderança local e o comprometimento da equipe de trabalho. Deve-se buscar o melhor custo-benefício de tempo e resultado, especialmente por não ser um trabalho tradicionalmente exercido nas unidades. 
Mais que isso. Necessário se faz o desenvolvimento de indicadores e metas à própria governança judiciária, que envolva o planejamento nos três níveis, estratégico, tático e operacional. Tais indicadores devem de alguma forma se relacionar aos indicadores ou sinalizadores que visualizem ou traduzam, pelo menos em parte, o impacto social da gestão judiciária, no aspecto da efetividade.

O quarto fator encontrado expõe que o resultado foi fruto da persistência dos líderes e da equipe de trabalho durante o período. Pode-se observar que desde 2014 a unidade judiciária aplicou o planejamento seguindo referida metodologia, de forma anual, mantendose praticamente a mesma equipe de trabalho e os mesmos líderes.

Alguns Tribunais demonstraram alta produtividade depois da insistência do uso de uma metodologia e sua melhoria contínua, como o Superior Tribunal de Justiça (BRASIL, STJ, 2018, p. 35) e o Tribunal Regional do Trabalho da $8^{\text {a }}$ Região (BRASIL, 2012) ao longo dos anos, em uma ascensão com tendência favorável. Esses Tribunais desenvolveram metodologias de gestão estratégica ao nível tático junto às unidades judiciais e/ou administrativas, como ação de governança judiciária, a fim de cumprir os macrodesafios determinados.

Outro efeito da gestão que trabalha de forma contínua tem foco no usuário do serviço e na sociedade, têm objetivos definidos, e uma visão de futuro clara, é sua interferência para o alcance da efetividade, ou seja, impacto social de suas ações.

Como um de seus elementos precípuos, a gestão das unidades, por sua vez, deve ter foco no usuário do serviço ou de forma genérica no cidadão, o que corresponde à perspectiva "Sociedade" exposto no Anexo do Planejamento Estratégico Nacional (BRASIL, 2014), e não simplesmente na gestão de processos, como se demonstra a ocorrência na maior parte do Judiciário brasileiro (OLIVEIRA, CUNHA, 2020).

Continuam as autoras (OLIVEIRA, CUNHA, 2020) ao esclarecerem que "[...] quanto mais detalhadas e desagregadas forem as informações, mais próximas da realidade se tornam e mais instrumentais para gestão de políticas públicas".

Nesse ponto, os planejamentos táticos descrevem a visão de futuro tratando de elementos constitucionais de interesse de todo o conjunto estatal como o desenvolvimento socioeconômico, incluindo o aspecto educacional, e expõem dentre os objetivos táticos definidos na perspectiva sociedade, indicadores e sinalizadores que contribuem para a preocupação com o índice de homicídios, a influência de melhores condições ao sistema 
carcerário, instalação de sistema de ensino à distância junto aos condenados a penas criminais, o desenvolvimento de cursos interdisciplinares nas Escolas de ensino médio, voltados a fomentar a reflexão sobre atos de preservação de conflitos sociais, valores ligados à cidadania, o desenvolvimento de oficinas de parentalidade, entre outros são elementos que denotam a preocupação da unidade não somente com os números de sentenças, mas também com a efetividade dos resultados junto à sociedade.

Por outro lado, foram encontradas algumas dificuldades e desafios aos gestores da referida unidade judiciária. Há grandes desafios na conjuntura externa, no sentido da dificuldade em se alcançar a visão de futuro, visto que a região tem um médio para baixo desenvolvimento socioeconômico. No plano interno, a principal adversidade está centrada ainda em reduzir o tempo de julgamento dos processos em menos de 365 dias (cíveis complexos) e 240 dias (criminais complexos), tempos considerados razoáveis para a grande maioria dos processos. Como caminhos para tal redução, pode ser que o sistema automatizado do e-Proc nacional e a instalação próxima do módulo de inteligência artificial possam impactar nos dados, conjugado com a manutenção da metodologia e atuação da liderança e das equipes. No plano da organização, a aplicação do modelo de forma isolada pode até gerar a boa percepção sobre a unidade e a influência positiva para as demais, porém, sem a força superior para impactar a mudança de comportamento em menor tempo, por ausência de uma política de governança institucional do Tribunal.

\section{CONSIDERAÇÕES FINAIS}

O processo judicial no Brasil, regra geral, não cumpre o princípio fundamental da razoável duração do processo. Há um problema de morosidade sistêmica.

A unidade judicial estudada desenvolveu uma metodologia de gestão tática anual, alinhando-se aos aspectos estratégicos do planejamento do Tribunal de Justiça do Tocantins e do Poder Judiciário nacional, desde o ano de 2014.

A unidade judiciária estudada demonstrou a produção de melhores resultados técnicos ao longo dos anos, em análise consigo por período, a partir do cumprimento das metas superiores, tendência de melhora de seus próprios resultados, melhores resultados frente às unidades judiciais de mesmo grupo e ainda em comparação com as unidades de Miranorte e Alvorada, ambas na justiça tocantinense, tradicionalmente com melhores resultados. 
O tempo de julgamento médio dos processos judiciais foi de 463 dias, em 2019, o que significa aproximadamente 01 ano e 03 meses, ainda acima dos valores aritméticos legais, porém, considerando sua média histórica dos cinco anos avaliados, redundou em uma diminuição de $62 \%$. Esse dado estaria próximo ao resultado do melhor Tribunal estadual do País com relação ao índice, TJSE (01 ano e 02 meses) e igual ao segundo melhor Tribunal estadual, TJDFT (01 ano e 03 meses) e superior ao do TJTO (01 ano e 08 meses).

Ao analisar os fatores que influenciaram a unidade judiciária de Colméia, foram identificados quatro elementos preponderantes.

Pode-se evidenciar a implementação de um sistema de gestão de governança, por uma metodologia, aplicando os conceitos e caminhos do planejamento tático e operacional em unidades judiciárias, a partir de instrumentos e ferramentas adaptadas à administração pública, formada por fases de coleta de dados, conhecimento da estratégia superior, diagnóstico, construção da filosofia gerencial e desenvolvimento de objetivos táticos, indicadores e metas táticos e setoriais, ações, acompanhamento de seus resultados, e reajuste contínuo das ações.

O modelo propiciou maior descentralização da gestão ao nível operacional, mas sem descuidar do acompanhamento contínuo, incentivou o papel da liderança na construção do planejamento, das ações e seu acompanhamento, e, inclusive, da liderança setorial, algo inovador no âmbito da justiça nacional.

A participação obrigatória de todos os colaboradores angariou maior envolvimento da equipe como atores, de maneira a propiciar maior possibilidade do desenvolvimento de ações inovadoras. Percebeu-se que com o passar dos anos, cada pessoa passava a entender melhor e a cooperar mais com o sistema de gestão.

Como último fator relevante aos resultados produzidos destaca-se a persistência da manutenção do sistema de gestão ao longo dos anos.

As dificuldades e desafios que merecem destaque estão calcados em três perspectivas: no âmbito externo, tendo em vista o contexto socioeconômico que envolve a circunscrição; no âmbito interno da própria unidade, atinente a necessidade de se buscar ainda maior celeridade no julgamento dos processos judiciais; e no âmbito interno da organização que faz parte, relacionado há a fragilidade do sistema de governança institucional do Tribunal de Justiça do Tocantins, o que faz prejudicar a produção dos melhores resultados de forma sistêmica. 
Por consequência, como se observou no corpo do trabalho, há a premente necessidade da capacitação contínua dos líderes ou de quem assuma as suas funções, no ambiente de gestão da governança e o desenvolvimento de plataformas digitais seguras e inteligentes para a alimentação correta e contínua das informações.

\section{REFERÊNCIAS}

ARRUDA, Samuel Miranda. O direito fundamental à razoável duração do processo. Brasília: Brasília Jurídica, 2006.

ATAIIDE JÚNIOR, Vicente de Paula. O novo juiz e a administração da justiça: repensando a seleção, a formação e a avaliação dos magistrados do Brasil. Curitiba: Juruá, 2006.

BASTO, Luis Eduardo Paschoal, et al. Organizações públicas brasileiras: a busca da eficiência, da eficácia ou da efetividade? Revista de Administração Pública (RAP). Rio de Janeiro, RJ: Fundação Getúlio Vargas-FGV, v. 27, n. 4, out./dez., 1993, p. 142-146.

BRASIL, Conselho Nacional de Justiça. Resolução n. 70, Brasília, 18 mar. 2009. Disponível em: < https://atos.cnj.jus.br/atos/detalhar/118>. Acesso em: 10 jun. 2020.

BRASIL, Conselho Nacional de Justiça. Resolução n. 198, Brasília, 01 jul. 2014. Disponível em: 〈http://www.cnj.jus.br/images/resol_gp_198_2014_copiar.pdf >. Acesso em: 02 fev. 2020.

BRASIL, Conselho Nacional de Justiça. Justiça em Números 2020: ano-base 2019, Brasília: CNJ, 2020. Disponível em: < https://www.cnj.jus.br/pesquisas-judiciarias/justica-emnumeros/>. Acesso em: 20 jul. 2020.

BRASIL, Constituição da República Federativa do Brasil. Diário Oficial da República Federativa do Brasil, Brasília, 05 out. 1988. Disponível em < www.planalto.gov.br/ccivil_03/constituicao/constituicao.htm>. Acesso em: 15 fev. 2020.

BRASIL, Ministério do Planejamento, Orçamento e Gestão (MPOG). Secretaria de Gestão Pública. Programa GESPÚBLICA, Modelo de Excelência em Gestão Pública, Brasília; MP, SEGEP, 2014.

BRASIL, Superior Tribunal de Justiça. Estratégia com uso do BSC: Balanced scorecard / Superior Tribunal de Justiça. Brasília: STJ, 2018.

BRASIL. Tribunal Regional do Trabalho da $8^{\text {a }}$ Região. Portaria GP n. 598, 31 de maio de 2012. Aprova a Metodologia de Alinhamento Estratégico por Painéis de Contribuição, com o apoio de Mapas Mentais - Método $\mathrm{APC}^{\mathrm{MM}}$, do Tribunal Regional do Trabalho da $8^{\mathrm{a}}$ Região. 
BRESSER-PEREIRA, Luiz Carlos. A reforma gerencial do Estado de 1995. Revista de Administração Pública (RAP). Rio de Janeiro, RJ: Fundação Getúlio Vargas-FGV, 2000, v. 34, n. 4, jul./ago., 2000, p. 07-26.

CAMPELO, Sebastião Marcos. Contribuição ao Estudo de um Modelo Conceitual de Gestão para a Justiça Federal da $5^{\text {a }}$ Região: um enfoque na adaptação no modelo de excelência em gestão pública. 171f. Dissertação de mestrado em ciências contábeis. Universidade de Brasília, 2007.

CASTRO, Rodrigo Batista. Eficácia, Eficiência e Efetividade na Administração Pública. In: Encontro da associação nacional de pós-graduação e pesquisa em administração ANPAD, 30, 2006, Salvador, BA. Disponível em:

<http://www.anpad.org.br/enanpad/2006/dwn/enanpad2006-apsa-840.pdf>. Acesso em: 30.02.2019.

COMISSÃO ECONÔMICA PARA AMÉRICA LATINA E CARIBE - CEPAL. Gestión de programas sociales en América Latina. Série Políticas Sociales, Santiago de Chile: Cepal, v. 1, n. 25, 1998. Disponível em: < http://www.cepal.org/pt-br/node/22600>. Acesso em: 08.02.2020.

CHIAVENATO, Idalberto. Teoria geral da administração. Abordagens prescritivas e normativas. 7.ed., v.1. Barueri: Manole, 2014.

DEOLINDO, Vanderlei. Planejamento estratégico em comarca do Poder Judiciário. 2010. 161f. Dissertação (Mestrado profissional em Poder Judiciário). Faculdade de Direito, Fundação Getúlio Vargas, Rio de Janeiro, 2010.

DRUCKER, Peter F. Administração em tempos turbulentos. 2. ed. São Paulo: Pioneira Editora, 1980.

FARIA, Renato Luiz Miyasato de. Princípio da razoável duração do processo e medidas de celeridade processual. São Paulo: LTr, 2013.

FERREIRA, Pedro Henrique Azevedo Lopes. Reforma Estatal, Accountability e Metas do Judiciário: as influências de uma administração baseada na busca por resultados no elemento qualitativo da prestação jurisdicional. 144f. Dissertação de mestrado em direito. Universidade Federal do Ceará, 2019.

FUIN, Tatiane de Abreu. O Planejamento Estratégico no Poder Judiciário e o Aperfeiçoamento na Prestação Jurisdicional. Dissertação de Mestrado. Universidade Estadual do Norte do Paraná. Centro de Ciências Sociais Aplicadas. Campus de Jacarezinho. Curitiba: UENP, 2013.

GIESKE, Hanneke; BUUREN, Arwin Van; BEKKERS, Victor. Conceptualizing public innovative capacity: a framework for assessment. The Innovation Journal: The Public Sector Innovation Journal, v. 21, n 1, 2016. 
MODESTO, Paulo. Notas para um debate sobre o princípio da eficiência. Revista do Serviço Público, Brasília, v.51, n.2, abr./jun. 2000, p. 105-120. Disponível em:

$<$ https://revista.enap.gov.br/index.php/RSP/article/view/328/334>. Acesso em: 02 de maio de 2017.

MOURA Luiz Otávio Borges de, FARIA, Ana Claudia Almeida Abreu; LOPES, Daniel de Godoy; BORGES, Elaine Nóbrega. Alinhamento Estratégico no STJ. In: Encontro de Administração da Justiça, 2019, Brasília. Anais EnAJUS 2019. Brasília: IBEPES, 2019.

NALINI, José Renato. Ética para um Judiciário transformador. São Paulo: Revista dos Tribunais, 2011.

NOGUEIRA, Eliane Garcia. Sistema de gestão de unidade judicial. Porto Alegre: Tribunal de Justiça do Estado do Rio Grande do Sul, 2011.

OLINTO, Lilian Bessa; SILVA, Lilian Rodrigues Carvalho da. A Implementação do Sistema de Gestão da Qualidade em Vara Judicial. In: MELO, José Wilson Rodrigues de; ROCHA, Suyene Monteiro da; FERNANDES, Suzidarly Ribeiro Teixeira. Caminhos e olhares sobre os direitos humanos. Curitiba: CRV, 2017. 258p. p. 175-189.

OLIVEIRA, Djalma de Pinho Rebouças de. Planejamento estratégico: conceitos, metodologia e práticas. 26. ed. São Paulo: Atlas, 2009.

OLIVEIRA, Fabiana Luci de; CUNHA, Luciana Gross. Os indicadores sobre o Judiciário brasileiro: limitações, desafios e o uso da tecnologia. Revista Direito GV. São Paulo, SP: Fundação Getúlio Vargas-FGV, v. 16, n. 1, Epub mar., 2020.

RIBEIRO, Alexei Alves. Qualidade da função administrativa na primeira instância do Poder Judiciário. In: PENTEADO, Luiz Fernando Wowk; PONCIANO, Vera Lúcia Feil (Orgs.).

Curso modular de administração da justiça. São Paulo: Conceito Editorial, 2002, p. 33-57.

RIBEIRO, Adriano da Silva. O magistrado gestor estratégico de unidades judiciárias. In: Processo, administração e jurisdição da justiça e forma consensuais de solução de conflitos [Recurso electrónico]. Zaragoza: Prensas de la Universidad de Zaragoza, 2019. (LEFIS series; 28). p. 179-202.

SANTOS, Zilmária Aires dos. Diagnóstico da Aplicação de Critérios para o Alcance de Produtividade e Celeridade na Distribuição de Atribuições dentro das Serventias Judiciais: o estudo do caso da comarca de Dianópolis-TO. 113f. Dissertação de mestrado em prestação jurisdicional e direitos humanos. Universidade Federal do Tocantins, 2017.

TOCANTINS. Tribunal de Justiça do Estado do Tocantins. Coordenadoria de Gestão Estratégica, Estatística e Projetos. Dados estatísticos dos anos de 2015 a 2019, Palmas, 2020.

VALLE, Marcus Vinícius Mendes do. Gestão estratégica de unidades judiciárias: desdobramento de $4^{\circ}$ nível - gestão judiciária aplicada. Belo Horizonte: Conhecimento, 2017. 